\title{
Cultura do consumismo: uma revisão bibliográfica sistemática
}

\section{Janaina Gonçalves Ferreira1, Maria Lícia dos Santos ${ }^{2}$ e Maria do Socorro Viana do Nascimento ${ }^{2}$,*}

\author{
${ }^{1}$ Instituto Federal de Educação, Ciência e Tecnologia de Goiás. Campus Ceres. Curso \\ de Licenciatura em Ciências Biológicas. Rodovia G0-154, km 03, S/№. Ceres-GO, \\ Brasil (76300-000). \\ ${ }^{2}$ Instituto Federal de Educação, Ciência e Tecnologia de Goiás. Campus Ceres. \\ Rodovia GO-154, $\mathrm{km}$ 03, S/No. Ceres-GO, Brasil (76300-000). *E-mail: \\ socorro.viana@ifgoiano.edu.br.
}

Resumo. O consumismo é um dos fatores contributivos e influenciadores aos danos ambientais e na qualidade de vida. Neste sentido a Educação Ambiental nos anos iniciais de escolarização do indivíduo se faz importante pois é preciso estimular o desenvolvimento de um conjunto de atitudes e capacidades no aluno, para que eles investiguem, questionem, construam e utilizem os meios disponíveis ganhando autonomia ao longo da aprendizagem. 0 presente artigo tem como finalidade apresentar uma revisão sistemática da literatura sobre o consumismo entre o público infantil em publicações realizadas nos últimos 29 anos. O levantamento de dados ocorreu entre setembro de 2019 e julho de 2020 e cruzou o unitermo Consumismo com Mídia, Propaganda, Consumismo infantil, Escola e Ambiente escolar e seus termos equivalente nas línguas inglesa e espanhola, destes foram selecionados 241 artigos, mas somente 18 artigos que responderam aos critérios de inclusão.

Palavras-chave: Consumismo infantil; Educação ambiental; Mídia; Ambiente escolar.

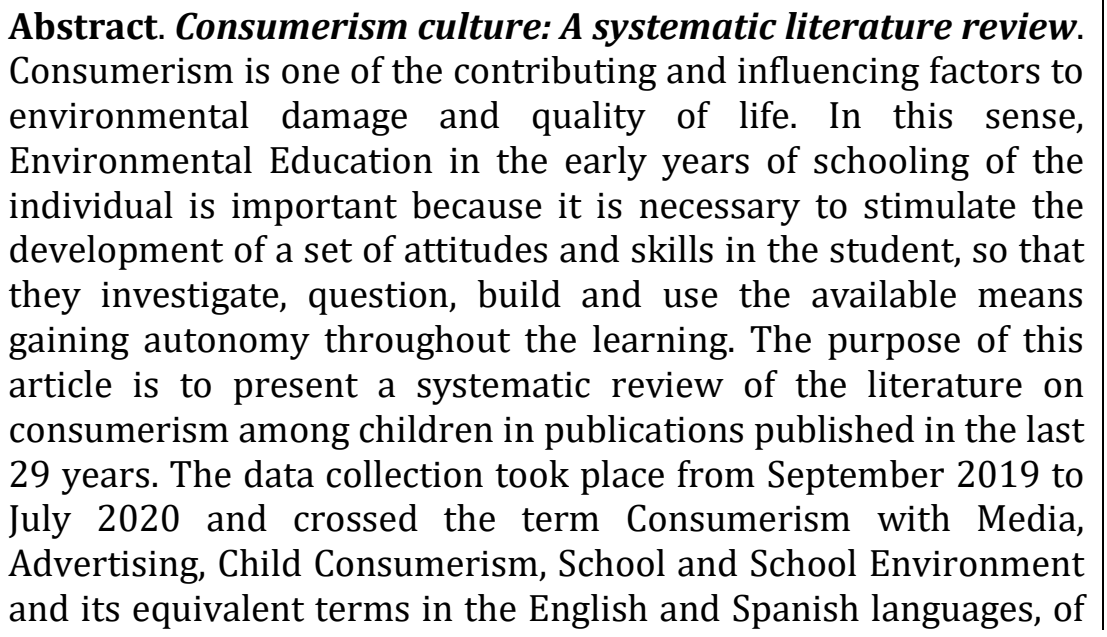

Recebido

$12 / 02 / 2021$

Aceito

$26 / 07 / 2021$

Disponível on line

$31 / 07 / 2021$

Publicado

$31 / 08 / 2021$

Acesso aberto

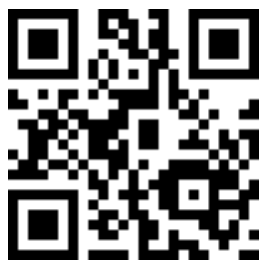

ORCID

(ㄷ) 0000-0002-5496-0555

Janaina Gonçalves

Ferreira

(D) 0000-0003-0330-5734

Maria Lícia dos Santos

(1) 0000-0001-8076-5561

Maria do Socorro

Viana do Nascimento

ISSN 2359-1412/RBGAS-2021-0013/2021/8/19/19/921

Rev. Bras. Gest. Amb. Sustent.

http://revista.ecogestaobrasil.net 
these 241 articles were selected but only 18 articles that met the inclusion criteria.

Keywords: Child consumerism; Environmental education; Media; School environment.

\section{Introdução}

O consumismo é um dos fatores contributivos e influenciadores aos danos ambientais e na qualidade de vida. A sociedade moderna utiliza o consumo de bens como forma de manifestar sua posição social, assim o consumo exagerado representa uma identidade social e um sentimento de que pertencemos a um grupo. A inovação e melhoria dos artigos de consumo geram maior expectativa de conforto e bem-estar com o objetivo de suprir a felicidade (Zanirato e Rotondaro, 2016).

Segundo Giacomini (1991), o gênero feminino possui maior sensibilidade ao consumo, deste modo ela se torna mais vulnerável para adquirir produtos supérfluos ou caros, na intenção de fornecer maior conforto e qualidade para si e a família. Giacomini, afirma ainda, que esse é um fenômeno humano individual ou grupal influenciado por empresas, instituições, grupos ou organizações, deste modo todos estão sujeitos a um excesso de estímulos para o consumo exagerado.

Dessa forma, a comunicação torna-se um dos principais estímulos para o consumismo, considerando que através da televisão, é possível ampliar o interesse e incentivar e influenciar de forma coletiva o consumo exacerbado. 0 mercado está sempre inovando para sustentar a clientela. Por ser um instrumento presente na maioria dos lares brasileiros (97\% dos domicílios) (IBGE, 2011) com média diária de $4 \mathrm{~h}$ em frente à TV, exposta ao estímulo constante ao consumo (Caron et al. 2015).

O Instituto Criança e Consumo (2017) traz dados alarmantes sobre o assédio do marketing voltado ao público infantil. E é por intermédio desse consumo precoce que as crianças estão sofrendo cada vez mais cedo com a obesidade infantil, erotização, adultização da infância, violência, estresse familiar, diminuição das brincadeiras e consumo de bebidas alcoólicas e tabaco, causando assim impactos negativos no seu desenvolvimento social e físico.

É através desse consumo exacerbado que o meio ambiente tem seus recursos rapidamente exauridos. Uma exploração exagerada, gera ameaças a estabilidade dos seus sistemas de sustentação (esgotamento de recursos naturais renováveis e não-renováveis, degradação do solo, perda de florestas e da biodiversidade, poluição da água e do ar e mudanças climáticas, entre outros).

De acordo com o PNUD (2014) mais da metade da população mundial (54\%) vive em áreas urbanas, mas somente $40 \%$ da população economicamente ativa é composta por produtores rurais, deste modo dois terços das pessoas em situação de extrema pobreza vivem em zonas rurais, e a sua subsistência depende em grande escala da agricultura e dos recursos naturais. Um dos efeitos desse consumo é pressão sobre os recursos hídricos, a degradação do solo juntamente com a falta de água são preocupações constantes, ainda em concordância o PNUD (2014), afirma que em 2025, a escassez de água afetará mais de 1,8 mil milhões de pessoas, atingindo principalmente os trabalhadores agrícolas e os agricultores pobres.

Não há dúvida de que a aglomeração populacional, os padrões de consumo e de deslocamento, e as atividades econômicas urbanas têm exercido intensos impactos sobre o meio ambiente em termos de consumo de recursos e eliminação de resíduos. E o resultado dessa exploração excessiva não é dividido igualmente para todos, onde apenas uma minoria da população se beneficia dessa riqueza (Cortez e Ortigoza, 2009). 
Cortez e Ortigoza (2009), deixa claro que toda essa exploração excessiva acarreta no processo "overshoot", um estágio no qual o meio ambiente não mais consegue se regenerar e prover recursos futuros. Deste modo é indispensável questões ambientais nos anos iniciais, pois contribuirá para a formação de cidadãos conscientes aptos para decidirem e atuarem na realidade socioambiental (Medeiros et al., 2011).

A expansão da sociedade de consumo, dominada pelo estilo de vida norteamericano, transformou o consumo em uma compulsão e um vício, estimulados pelas forças do mercado, da moda e da propaganda (Cortez e Ortigoza, 2009), resultando em uma exposição à publicidade e atratividade para a publicidade de bebidas alcoólicas, relacionando-a com uma maior expectativa de consumo futuro e com um consumo maior e mais precoce, principalmente entre adolescentes e adultos jovens (Pinsky, 2019).

A alimentação merece uma atenção especial, pois os estudos apontaram que a mídia tem exercido papel fundamental na formação de novos hábitos alimentares, causando influência no público infantil. Conforme descrito por Araújo et al. (2006), as crianças que passam muitas horas expostas à televisão, são mais vulneráveis aos anúncios de alimentos de alto valor calórico, além do fato de não estarem praticando atividades físicas, situação esta que predispõe para o aumento do risco para obesidade e sobrepeso (Pipitone, 2015).

Em conformidade com Mendes et al. (2006), no Brasil, o excesso de peso e a obesidade já atingem mais de $30 \%$ da população adulta, sendo acompanhada por maior morbidade e menor longevidade dos indivíduos. Na infância este problema crescente chega a atingir de $25 \%$ a $30 \%$ da população infantil nos países ricos. Por isso há uma necessidade de conscientização, pois a educação deve ser ressaltada como elemento para a transformação da sociedade, tornando viável o desenvolvimento de uma nova ética.

Para a UNESCO (2005, p. 44), "Educação Ambiental é uma disciplina bem estabelecida que enfatiza a relação dos homens com o ambiente natural, as formas de conservá-lo, preservá-lo e de administrar seus recursos adequadamente".

A Educação Ambiental nos anos iniciais de escolarização do indivíduo se faz importante, visto que para Medeiros et al. (2011), é mais fácil conscientizar as crianças sobre as questões ambientais do que os adultos, assim sendo a escola irá preparar o indivíduo para exercer sua cidadania, possibilitando a ele uma participação efetiva nos processos sociais, culturais, políticos e econômicos

0 presente trabalho tem por motivação a importância da educação ambiental nas séries iniciais. A disciplina tem como objetivo promover pensamentos críticos a respeito dos problemas ambientais enfrentados e futuros.

Deste modo, é preciso estimular o desenvolvimento de um conjunto de atitudes e capacidades no aluno, para que eles investiguem, questionem, construam e utilizem os meios disponíveis ganhando autonomia ao longo da aprendizagem. 0 presente artigo tem como finalidade apresentar uma revisão sistemática da literatura sobre o consumismo entre o público infantil (idade inferior a 12 anos) em publicações realizadas nos últimos 29 anos.

\section{Educação ambiental}

A educação ambiental surge da preocupação da sociedade com o futuro da vida e com a qualidade da existência das presentes e futuras gerações. A EA se transforma em uma proposta educativa em sentido forte, onde dialoga com o campo educacional, com suas tradições, teorias e saberes (Carvalho, 2006).

Segundo Jacobi (2003), a "educação ambiental deve ser vista como um processo constante de aprendizagem que valoriza as diversas formas de conhecimento e forma cidadãos com consciência local e planetária".

Sorrentino (1998) ressalta a importância das Conferências dedicadas especialmente à educação ambiental, que ocorreram nos anos de 1972-1977, que 
configurou a educação ambiental como importante instrumento de promoção da consciência ambiental e estratégia fundamental para se conseguir criar e aplicar formas mais eficazes e sustentáveis de integração sociedade/natureza.

No Brasil a educação ambiental foi instituída pela Lei no 6.938/1981 (Brasil, 1981), que dispõe sobre a Política Nacional do Meio Ambiente (PNMA), e definiu como princípios a promoção da educação ambiental em caráter formal, em todos os níveis de ensino, bem como de modo não formal, na educação comunitária, com o objetivo de capacitar os cidadãos para a promoção da defesa do meio ambiente. Mais adiante, a Lei no 9.795/1997 (Brasil, 1997), que dispõe sobre a educação ambiental, institui a Política Nacional de Educação Ambiental (PNEA), conceitua a educação ambiental como:

Art. 1o Entendem-se por Educação Ambiental os processos por meio dos quais o indivíduo e a coletividade constroem valores sociais, conhecimentos, habilidades, atitudes e competências voltadas para a conservação do meio ambiente, bem de uso comum do povo, essencial à sadia qualidade de vida e sua sustentabilidade.

Essa legislação integrante das políticas públicas, ao indicarem a necessidade de que a educação ambiental seja também desenvolvida no ensino formal, ou seja, na educação escolar, buscam inserir a educação ambiental no processo de formação dos indivíduos, compreendendo a escola como "forma principal e dominante de educação" (Saviani, 2015, p. 35).

Por ser um processo no qual o educando passa a obter conhecimento sobre as questões ambientais, a educação ambiental possibilita uma nova visão sobre o meio ambiente, se tornando um agente transformador em relação à conservação ambiental. Portanto, a educação ambiental nas escolas irá contribuir para a formação de cidadãos conscientes, aptos para decidirem e atuarem na realidade socioambiental de um modo comprometido com a vida, com o bem-estar de cada um e da sociedade (Medeiros et al., 2011).

O Brasil, dentro do panorama da América Latina, se configura como o único país com uma política de educação ambiental, fato que se destaca como uma grande conquista para o cenário ambiental do nosso país. Ainda que, esta norma jurídica não seja aplicada na íntegra, a mesma é relevante, pois tem a iniciativa de proteger o ambiente (Dias, 2004).

\section{Consumo e sustentabilidade}

Na definição do Programa das Nações Unidas para o Meio Ambiente (PNUD, 2014), consumo sustentável significa o

fornecimento de serviços e de produtos correlatos que preencham as necessidades básicas e deem uma melhor qualidade de vida, ao mesmo tempo em que se diminui o uso de recursos naturais e de substâncias tóxicas, assim como as emissões de resíduos e de poluentes durante o ciclo de vida do serviço ou do produto, de forma a não ameaçar as necessidades das gerações futuras (PNUD, 2014).

De modo geral, a sustentabilidade se caracteriza por ser um termo amplo, o que a torna cada vez mais presente na vida da sociedade moderna. Em resumo, é a utilização dos recursos que a natureza oferece, no mais eficiente e eficaz possível, economicamente, buscando o menor impacto no equilíbrio entre o meio ambiente e o modo de vida humano.

Entretanto, Boff (2009) afirma que, o conceito de "consumo sustentável", é transmitido todos os dias por notícias, revistas e anúncios, mas que não é suficiente para conscientizar a sociedade contemporânea. Já são mais de sete bilhões de habitantes da Terra, vivendo onde o importante é acumular recursos e bens, independentemente de qualquer forma e origem que eles tenham. Em uma sociedade capitalista vende o preceito 
que só se pode viver bem quando todas as necessidades, mesmo que venham do ego e da ganância humana, sejam realizadas.

Ainda de acordo com Boff (2009), sustentável seria o crescimento econômico e o desenvolvimento social, que de acordo com a comunidade da vida, produzir segundo a capacidade do bioma de atender com eficiência as demandas de nossa geração, sacrificando o capital natural e aberto às demandas das gerações do futuro.

Arnt (2010) alega que os economistas se perguntam como alocar recursos escassos com usos alternativos e a natureza não parece ser um recurso escasso, bem como afirma ainda que, certamente não era há duzentos anos no passado, mas essa escassez de bens naturais é um fenômeno recente que acontece com a degradação do meio ambiente. Contudo, estamos percebendo que este bem, a natureza, está sendo destruída pelo homem onde temos um problema não só econômico como também natural, onde biomas, animais estão sendo extintos.

\section{Consumo e consumismo}

Cortez e Ortigoza (2009) sustenta que o consumismo é o ato de consumir produtos ou serviços, muitas vezes, sem consciência, que há várias discussões a respeito de como a propaganda e a publicidade exercem nas pessoas, induzindo-as ao consumo, mesmo que não necessitem de um produto comprado. Além disso, Cortez e Ortigoza (2009) define ainda que o "consumo" é entendido como as aquisições racionais, controladas e seletivas baseadas em fatores sociais e ambientais e no respeito pelas gerações futuras. Já o consumismo pode ser ressaltado como uma dependência para consumir.

O World Watch Institute (Instituto Akatu, 2010) reconhece que o consumo é normal. Todas as pessoas ou seres vivos necessitam consumir para sobreviver. A coisa que não é procedente é o consumismo, que é a tendência atual que leva as pessoas a buscar o significado da vida e aceitação dos outros principalmente através do que eles consomem.

Ao longo dos anos, a evolução econômica permitiu o aumento entre classes e bens de consumo sociais agora estão disponíveis para todos. As classes mais baixas entram no ritmo do consumismo e a mídia se torna um grande aliado da disseminação dessa nova realidade. Lipovetsky (2007) declara que a concepção de sociedade de consumo tange atualmente como um indício onde, se assemelha com uma das competências mais representativa da nova ordem econômica e da vida cotidiana das sociedades contemporâneas.

Para Lazzarini e Gunn (2002), atualmente são perceptíveis modelos insustentáveis tanto na produção quanto no consumo, que na verdade são dois lados da mesma moeda cujos relacionamentos são interdependentes. Aquela insustentabilidade é baseada em métodos indevidos socialmente e predadores ambientais porque não atendem às carências fundamentais da população e que precisa do uso intensivo de recursos naturais, poluição, degradação dos ecossistemas naturais, incluindo a eliminação de resíduos pósconsumo.

Logarezzi (2006) salienta que a progressista procura por novas mercadorias para consumo, com vistas a agradar tanto necessidades reais e desejos produzidos socialmente com a ajuda da publicidade, promove o elevado da produção e diversidade de produtos.

Nesse contexto, a questão dos resíduos foi apontada por problemas ambientais como um dos mais graves problemas ambientais urbanos presentes. Entendendo a necessidade de gerenciamento integrado de resíduos sólidos levaram à criação da chamada Política da 3R (reduzir, reutilização e reciclagem), que "inspira técnica e pedagogicamente os meios de abordando a questão do lixo", como assegura Layrargues (2002). Contudo, em geral, a ênfase nos programas de coleta seletiva é a reciclagem e reciclagem em vez de reduzir o consumo, o que caracteriza o principal problema. 


\section{Metodologia}

Para a realização deste estudo, foi realizado uma revisão sistemática de literatura que tem o propósito uma investigação focada que pretende identificar, selecionar, avaliar e sintetizar os índices relevantes. As bases de estudo consultadas foram SciELO (Scientific Electronic Library Online) e Periódico CAPES.

O levantamento de dados ocorreu de setembro de 2019 a julho de 2020 . A busca foi feita para o período compreendido entre 1990 e 2019, cruzando-se o unitermo Consumismo com Mídia, Propaganda, Consumismo infantil, Escola e Ambiente escolar e seus termos equivalentes nas línguas inglesa e espanhola. Foram selecionados trabalhos com a abordagem sobre a influência da mídia sobre o consumismo infantil e formas de conscientização através da educação ambiental, além de serem confiáveis e reconhecidos cientificamente. Entre os motivos para a não seleção dos trabalhos estavam; não abordagem do assunto proposto, não completo, ou não disponível online gratuitamente, outros idiomas além de português, inglês e espanhol e por serem distintos de publicação.

\section{Resultados e discussão}

A revisão bibliográfica revelou inicialmente um total de 241 estudos com unitermo Consumismo com Mídia, Propaganda, Consumismo infantil, Escola e Ambiente escolar e seus termos equivalentes nas línguas inglesa e espanhola, destes, 100 foram excluídos pela não abordagem do assunto, ou seja, por não tratarem da influência da mídia sobre o consumismo infantil e formas de conscientização através da educação ambiental, 25 foram excluídos por não estarem completos, 18 por estarem em outro idioma, além do português, inglês e espanhol, e 80 por serem distintos como editoriais, resenhas e resumos (Figura 1).

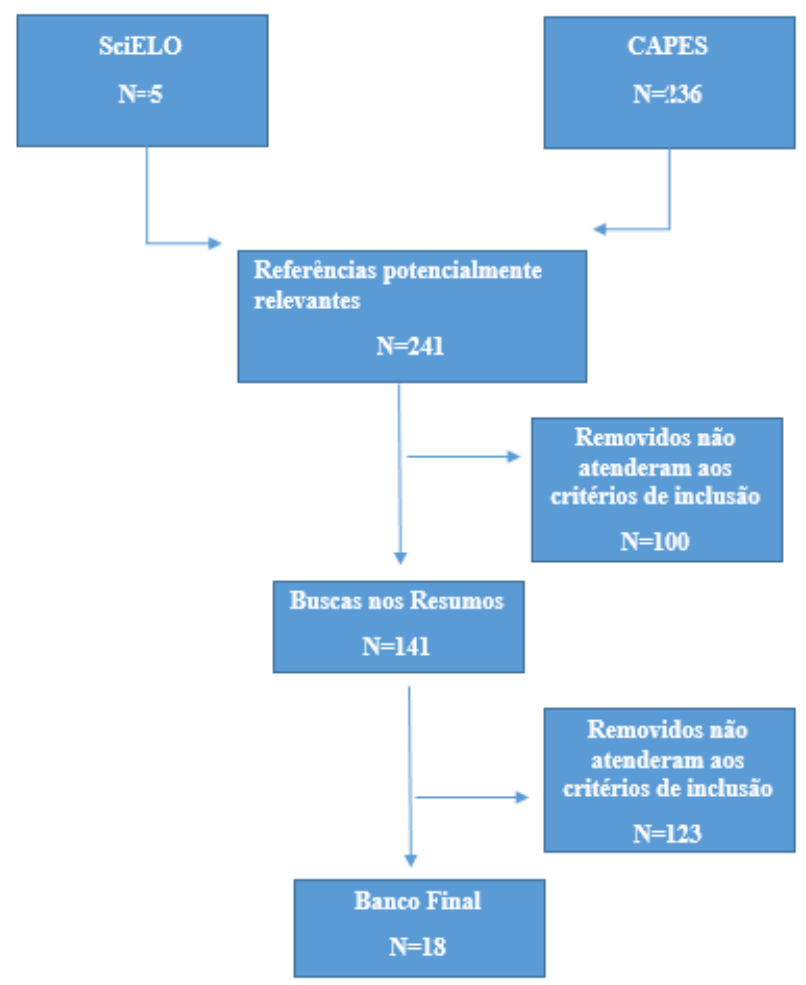

Figura 1. Estratégias de busca. 
Os 18 artigos selecionados que responderam aos critérios de inclusão foram listados na Tabela 1.

Tabela 1. Distribuição dos artigos selecionados por ano de publicação.

\begin{tabular}{|c|c|c|c|}
\hline Autor & $\begin{array}{c}\text { Ano de } \\
\text { publicação }\end{array}$ & Título & $\begin{array}{l}\text { Quantidade de } \\
\text { artigos }\end{array}$ \\
\hline Giacomini Filho & 1991 & Consumidor versus propaganda. & 1 \\
\hline Sorrentino & 1998 & $\begin{array}{l}\text { Educação, meio ambiente e cidadania: reflexões e } \\
\text { experiências. }\end{array}$ & 1 \\
\hline Layrargues & 1999 & $\begin{array}{l}\text { A resolução de problemas ambientais locais deve } \\
\text { ser um tema-gerador ou a atividade-fim da } \\
\text { educação ambiental? }\end{array}$ & 1 \\
\hline Guimarães & 2001 & $\begin{array}{l}\text { Educação ambiental } \\
\text { sustentabilidade. }\end{array}$ & 1 \\
\hline Lazzarini e Gunn & 2002 & 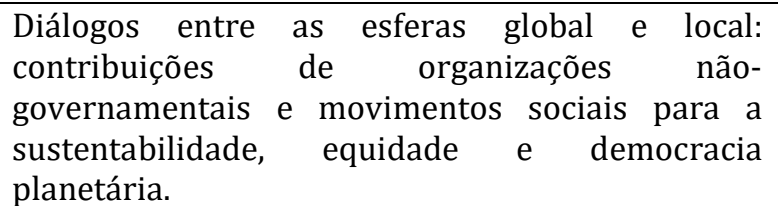 & 1 \\
\hline Carvalho & 2004 & $\begin{array}{l}\text { Educação ambiental: a formação do sujeito } \\
\text { ecológico. }\end{array}$ & 1 \\
\hline MMA & 2005 & Consumo sustentável: manual de educação. & 1 \\
\hline Araújo et al. & \multirow{2}{*}{2006} & $\begin{array}{l}\text { Avanços na norma brasileira de comercialização } \\
\text { de alimentos para idade infantil. }\end{array}$ & 2 \\
\hline Logarezzi & & $\begin{array}{lllll}\begin{array}{l}\text { Educação ambiental em resíduo: o foco da } \\
\text { abordagem. }\end{array} & \end{array}$ & \\
\hline Lipovetsky & 2007 & $\begin{array}{l}\text { A felicidade paradoxal: ensaio sobre a sociedade } \\
\text { de hiperconsumo. }\end{array}$ & 1 \\
\hline Pinsky e Jundi & 2008 & $\begin{array}{l}\text { O impacto da publicidade de bebidas alcoólicas } \\
\text { sobre o consumo entre jovens: revisão da } \\
\text { literatura internacional. }\end{array}$ & 1 \\
\hline Boff & \multirow{2}{*}{2009} & $\begin{array}{l}\text { Saber cuidar: Ética do humano: compaixão pela } \\
\text { Terra. }\end{array}$ & 2 \\
\hline $\begin{array}{l}\text { Cortez e } \\
\text { Ortigoza }\end{array}$ & & $\begin{array}{l}\text { Da produção ao consumo: } \\
\text { socioambientais no espaço urbano. }\end{array}$ & \\
\hline Medeiros et al. & 2011 & $\begin{array}{l}\text { A Importância da educação ambiental na escola } \\
\text { nas séries iniciais. }\end{array}$ & 1 \\
\hline Caron et al. & \multirow[b]{2}{*}{2015} & $\begin{array}{l}\text { Afinal, somos ou não somos uma sociedade de } \\
\text { consumo? Consequências para a saúde. }\end{array}$ & 2 \\
\hline Saviani & & $\begin{array}{l}\text { O conceito dialético de mediação na pedagogia } \\
\text { histórico-crítica em intermediação com a } \\
\text { psicologia histórico-cultural. }\end{array}$ & \\
\hline $\begin{array}{l}\text { Zanirato e } \\
\text { Rotondaro }\end{array}$ & 2016 & Consumo, um dos dilemas da sustentabilidade. & 1 \\
\hline Alves et al. & 2019 & $\begin{array}{l}\text { A influência da mídia no consumismo infantil: uma } \\
\text { revisão de literatura. }\end{array}$ & 1 \\
\hline
\end{tabular}

\section{Influência da mídia sobre o consumismo infantil}

A mídia possui forte influência sobre o consumismo infantil, principalmente nas questões mais simples, como no aleitamento materno onde existem diversas causas do abandono devido a influência da propaganda sobre fórmulas de leite integral. A influência 
do marketing utilizado pelas indústrias sobre as práticas de alimentação infantil vem causando consequências no desmame precoce, na desnutrição e na mortalidade infantil. (Araújo et al., 2006). Outra forte influência é o marketing de bebidas alcoólicas que interfere diretamente na vida dos jovens e adultos, causando dependência e morte (Pinsky, 2008).

O consumo qualifica o indivíduo e as identidades que são produzidas através do consumo. Neste contexto, ser alguém é ser consumidor. 0 direito do consumidor se sobrepõe e se torna referência inclusive para o julgamento sobre direitos sociais, como nos casos de judicialização em saúde no Brasil (Caron, 2015)

Os meios de comunicação de massa tendem a enaltecer o elevado padrão de consumo da classe dominante. De acordo com Campos e Souza (2003) isto está associado com a ideia de liberdade e de independência, difundindo o consumismo como uma "liberdade de escolha do indivíduo". Sendo assim, os meios de comunicação impõem seu grande fluxo de mensagens ideológicas, causando o conformismo e a manipulação das massas. Os artefatos tecnológicos são feitos para não pensar e perder tempo, como também para operar e viver num ativismo na qual é impossível a autonomia e a liberdade, principalmente quando o destinatário da mensagem midiática é a criança, pois esta é mais propensa a ingenuidade e credulidade.

O tema "influência da mídia" é de grande relevância, pois os meios de comunicação em geral, quando utilizados de forma deliberada, principalmente no que refere-se às crianças, formam valores e costumes que se tornam referência para estes futuros adultos (Alves et al., 2019).

O Manual da Educação (MEC, 2005) reforça que as crianças e os jovens são ainda mais suscetíveis à publicidade do que os adultos. Isso ocorre porque eles ainda não têm uma mentalidade crítica bem desenvolvida, nem a capacidade de ver o que está por trás da mensagem publicitária. E como os jovens constituem um grupo cada vez maior de consumidores em potencial, eles são um importante alvo na mira das empresas de publicidade.

As crianças de hoje sofrem influência da globalização cultural no mundo dos brinquedos. A boneca americana, as figurinhas de guerreiros intergalácticos, bonecos japoneses e tantos outros heróis fabricados pela mídia são brinquedos encontrados em qualquer lugar do mundo. Com essa globalização, que se expressa não somente nos brinquedos, mas também na publicidade de um grande número de produtos, as particularidades de cada povo e cada cultura tendem a apagar-se (MEC, 2005).

A criança como indivíduo concreto, seu interesse coincide com a apropriação das objetivações humanas, isto é, o conjunto dos instrumentos materiais e culturais produzidos pela humanidade e incorporados à forma social de que a criança participa. Nesse sentido, a publicidade massiva desempenhou e continua a desempenhar um papel importante. É natural que as crianças passem a valorizar e desejar aqueles mesmos brinquedos que veem na televisão, pois elas não têm discernimento suficiente para compreender que uma simples boneca possa significar a substituição de valores culturais e a importação de um estilo de vida que pode não ser o mais adequado para ela (Saviani, 2015).

Ao mesmo tempo em que vemos esse padrão de consumo disseminado pela globalização cultural vemos também uma reação da sociedade na tentativa de contrapor essa homogeneização de valores e culturas, ainda que numa escala menor e artesanal de produtos que valorizem aspectos culturais e raciais antes negligenciados como é o caso da fabricação de bonecas negras. 


\section{Hábitos de consumo exacerbado e seus problemas}

Alves et al. (2019) em trabalho de revisão de literatura verificaram que há um consenso entre os pesquisadores que abordam o papel da mídia no consumo infantil. 0 discurso midiático tem implicado no estabelecimento de valores que favorecem a construção da "adultização" precoce da criança, contribuindo também na formação de consumidores infantis em uma "sociedade espetacularizada", na qual as crianças são incentivadas por meio da publicidade, a participarem de concursos de beleza e tornaremse "modelos" de corpo, gênero e sexualidade, para o consumo de produtos de beleza ditos para o público-infantil, e as crianças se tornam, ao mesmo tempo, consumidoras e objetos de consumo.

Giacomini (1991) observou que alguns aspectos da propaganda, entre eles as pessoas de baixa renda dão mais importância à propaganda do que as de alta renda, mulheres acreditam mais na propaganda do que os homens, pessoas com grau de instrução mais elevados são mais meticulosas ao analisarem uma propaganda, no entanto, esses mesmos consumidores acreditam que publicações falsas deveriam ser passíveis de punição e retratação pública.

O hábito de consumo exacerbado e altos padrões de produção e consumo nos faz pensar nas gerações que ainda virão, em suas necessidades, saímos assim dos problemas advindos do padrão de consumo e seus danos na micro escala e nos deparamos com os danos em escala planetária.

A grande demanda gerada pelo consumo exacerbado nos levam a pensar nas relações entre consumo e meio ambiente e em caminhos para diminuir a tensão causada pelo apelo ao consumo (Zanirato e Rotondaro, 2016). O Consumo exagerado possui sérios agravantes como, aquecimento global do planeta, devastação das florestas, extermínio da biodiversidade, estes problemas são decorrência, em grande parte, do atual estágio de desenvolvimento global, dos altos padrões de produção e consumo (Sorrentino, 1998).

Deste modo se faz necessário construir uma sociedade mais sustentável, na qual se fortaleça, a partir da crítica ao consumismo, a ideia de que os atuais padrões de consumo estão nas raízes da crise ambiental. (Cortez e Ortigoza, 2009). Boff (2009) condiciona a saúde planetária a uma alfabetização ecológica, e que se reveja os hábitos de consumo. Logarezzi (2006) alerta que um consumo responsável não deve procurar apenas o desenvolvimento de novos comportamentos individuais e coletivos quanto ao ato de consumir, deve-se moldar novos hábitos de um consumo responsável, onde deve-se envolver também reflexões individuais e intersubjetivos sobre a realidade e a construção participativa de processos que apontem para uma revisão profunda dos valores que regem a vida em sociedade.

\section{0 tema consumismo infantil no ambiente escolar}

Enquanto ação educativa, educação ambiental tem sido importante moderadora entre a esfera educacional e o campo ambiental, dialogando com os novos problemas gerados pela crise ecológica e produzindo reflexões, concepções, métodos e experiências que visam construir novas bases de conhecimento e valores ecológicos nesta e nas futuras gerações (Carvalho, 2004).

Nessa direção, a educação para a cidadania representa a possibilidade de motivar e sensibilizar as pessoas para transformar as diversas formas de participação em potenciais fatores de dinamização da sociedade e de ampliação do controle social, inclusive pelos setores menos mobilizados.

Trata-se de criar as condições para a ruptura com a cultura política dominante e para uma nova proposta de sociabilidade baseada na educação para a participação, está se concretizará principalmente pela presença crescente de uma pluralidade de atores que, através da ativação do seu potencial de participação terão cada vez mais condições de intervir consistentemente e sem tutela nos processos decisórios de interesse público, 
legitimando e consolidando propostas de gestão baseadas na garantia de acesso à informação e na conciliação de canais abertos para a participação que, por sua vez, são pré condições básicas para institucionalização do controle social (Guimarães, 2001; Santos e Sato, 2001).

Entende-se a importância dos responsáveis, bem como profissionais de psicologia envolvidos com a criança, estarem conscientes de que a influência da mídia se configura numa questão de interesse social, devido à possibilidade de intervenção direta e/ou indireta, a depender de suas proporções, no desenvolvimento infantil (Alves et al., 2019).

A educação possui a capacidade de promover valores, trata-se de um processo que envolve transformações no sujeito que aprende e incide sobre sua identidade e posturas diante do mundo. Desenvolvendo habilidades como mais cooperação, e menos competitividade, assim se pode ter grandes expectativas sobre a recuperação do meio ambiente, ou o congelamento da destruição dos bens naturais que ainda não entraram em extinção no nosso planeta (Medeiros et al., 2011).

Layrargues (1999) aponta para o surgimento de estratégia de resolução de problemas ambientais locais, onde a ação local representa a melhor oportunidade tanto do enfrentamento dos problemas ambientais, como da compreensão da complexa interação dos aspectos ecológicos com os político-econômicos e socioculturais da questão ambiental. A partir desta ótica, para além de se trabalhar pontualmente questões globais e distantes da realidade, como a redução da camada de ozônio, as queimadas nas florestas tropicais, o comércio do lixo tóxico, a desertificação ou a extinção de espécies, o educador deve priorizar em sua prática a pauta dos problemas locais que afetam as suas comunidades.

A resolução de problemas ambientais locais carrega um valor altamente positivo, pois foge da tendência desmobilizadora da percepção dos problemas globais, distantes da realidade local, e parte do princípio de que é indispensável que o cidadão participe da organização e gestão do seu ambiente de vida cotidiano (Layrargues, 1999).

\section{Conclusão}

A ideia de que o consumo de produtos representa qualidade de vida e sociedade evoluída tem caído por terra frente aos grandes danos ambientais, e não menos importante a interferência sob o poder de escolha e saúde física e mental. Mas atrelado ao consumo exacerbado está a propaganda, que nos leva na busca incessante da felicidade intangível. 0 público mais suscetível ao apelo da mídia é sem dúvida o público infantil devido ao fato da criança não ter uma mentalidade crítica, sem conseguir distinguir o que está por trás da mensagem publicitária.

O levantamento dos dados mostra que o tema "consumismo e educação ambiental" é pouco abordado na educação e, principalmente, na educação para o consumo, que consequentemente leva a uma falha, pois a educação deve ter a capacidade de promover valores, não sendo somente um meio de informar, trata-se de um processo que envolve transformações no sujeito que aprende e incide sobre sua identidade e posturas à frente do mundo, diante disso fica claro a real importância de se trabalhar educação para o consumo desde a educação infantil pois, é desde pequeno que se aprende a preservar.

\section{Conflito de interesses}

As autoras declaram não haver conflito de interesses. 


\section{Referências}

Alves, S. C. S.; Gravatá, R. C. F.; Fernandes, S. C. S. A influência da mídia no consumismo infantil: uma revisão de literatura. Revista Brasileira de Iniciação Científica, v. 6, n. 7, p. 41-56, 2019.

Araújo, M. F. M; Rea, M. F; Pinheiro, K. A; Schmitz, B. A. Avanços na norma brasileira de comercialização de alimentos para idade infantil. Revista de Saúde Pública, v. 40, n. 3, p. 513-520, 2006. https://doi.org/10.1590/S0034-89102006000300021

Arnt, R. 0 que os economistas pensam sobre sustentabilidade. São Paulo: Editora 34, 2010.

Boff, L. Saber cuidar: ética do humano - compaixão pela Terra. 4. ed. Petrópolis: Vozes, 2009.

Brasil. Lei no 6.938, de 31 de agosto de 1981. Dispõe sobre a Política Nacional do Meio Ambiente, seus fins e mecanismos de formulação e aplicação, e dá outras providências. Disponível em: <http://www.planalto.gov.br/ccivil_03/leis/L6938compilada.htm>. Acesso em: 08 ago. 2020.

Brasil. Lei no 9.795, de 27 de abril de 1999. Dispõe sobre a educação ambiental, institui a Política Nacional de Educação Ambiental e dá outras providências. Disponível em: <http://www.planalto.gov.br/ccivil_03/leis/19795.htm>. Acesso em: 08 ago. 2020.

Campos, C. C. G.; Souza, S. J. Mídia, cultura do consumo e constituição da subjetividade na infância. Psicologia: Ciência e Profissão, v. 23, n. 1, p. 12-21, 2003. https://doi.org/10.1590/S1414-98932003000100003

Caron, E.; Lefevre, F.; Lefevre, A. M. C. Afinal, somos ou não somos uma sociedade de consumo? Consequências para a saúde. Ciência \& Saúde Coletiva, v. 20, n. 1, p. 145-153, 2015. https://doi.org/10.1590/1413-81232014201.18812013

Carvalho, I. C. M. Educação ambiental: a formação do sujeito ecológico. São Paulo: Cortez, 2004.

Cortez, A. T. C.; Ortigoza, S. A. G. (Orgs.). Da produção ao consumo: impactos socioambientais no espaço urbano. São Paulo: Editora UNESP; Cultura Acadêmica, 2009.

Dias, G. F. Educação ambiental: princípios e práticas. 9. ed. São Paulo: Gaia, 2004.

Giacomini Filho, G. Consumidor versus propaganda. São Paulo: SUMMUS, 1991.

Guimarães, M. Educação ambiental e a gestão para a sustentabilidade. In: Santos, J. E.; Sato, M. (Org.). A contribuição da educação ambiental à esperança de Pandora. São Carlos: RIMA, 2001. p. 183-195.

IBGE - Instituto Brasileiro de Geografia e Estatística. Pesquisa nacional por amostra de domicílios: PNAD. Rio de Janeiro: IBGE, 2011. <https://www.ibge.gov.br/>. Acesso em: 08 ago. 2019.

Instituto Akatu. Instituto Akatu e Worldwatch Institute (WWI) apresentam relatório "Estado do Mundo-2010". Disponível em: <https://www.akatu.org.br/releases/institutoakatu-e-worldwatch-institute-wwi-apresentam-relatorio-estado-do-mundo-2010/>.

Acesso em: 08 ago. 2020.

Instituto Criança e Consumo. 2017: um ano veloz e intenso. 2017. Disponível em: $<$ https://criancaeconsumo.org.br/noticias/2017-um-ano-veloz-e-intenso/>. Acesso em: 08 ago. 2020. 
Jacobi, P. Educação ambiental, cidadania e sustentabilidade. Cadernos de Pesquisa, n. 118, p. 189-205, 2003. https://doi.org/10.1590/S0100-15742003000100008

Layrargues, P. P. A resolução de problemas ambientais locais deve ser um tema-gerador ou a atividade-fim da educação ambiental? In: Reigota, M. (Org.). Verde cotidiano: o meio ambiente em discussão. Rio de Janeiro: DP\&A, 1999. p. 131-148.

Layrargues, P. P. 0 cinismo da reciclagem: o significado ideológico da reciclagem da lata de alumínio e suas implicações para a educação ambiental. In: Castro, R. S.; Layrargues, P. P.; Loureiro, C. F. B. (Orgs.). Educação ambiental: repensando o espaço da cidadania. São Paulo: Cortez, 2002.

Lazzarini, M.; Gunn, L. Consumo sustentável. In: Born, R. H. (Coord.). Diálogos entre as esferas global e local: contribuições de organizações não-governamentais e movimentos sociais para a sustentabilidade, equidade e democracia planetária. São Paulo: Peirópolis, 2002.

Lipovetsky, G. A felicidade paradoxal: ensaio sobre a sociedade de hiperconsumo. São Paulo: Companhia das Letras, 2007.

Logarezzi, A. J. M. Educação ambiental em resíduo: o foco da abordagem. In: Cinquetti, H. C. S.; Logarezzi, A. (Orgs.). Consumo e resíduo: fundamentos para o trabalho educativo. São Carlos: EdUFSCAR, 2006. p. 119-144.

Medeiros, A. B.; Mendonça, M. J. S. L.; Sousa, G. L.; Oliveira, I. P. A importância da educação ambiental na escola nas séries iniciais. Revista Faculdade Montes Belos, v. 4, n. 1, p. 1-17, 2011.

Mendes, M. J. F. L.; Alves, J. G. B.; Alves, A. V.; Siqueira, P. P.; Freire, E. F. C. Associação de fatores de risco para doenças cardiovasculares em adolescentes e seus pais. Revista Brasileira de Saúde Materna e Infantil, v. 6, suppl. 1, p. 549-554, 2006. https://doi.org/10.1590/S1519-38292006000500007

MMA - Ministério do Meio Ambiente. Consumo sustentável: manual de educação. Brasília: Consumers International/MMA/MEC/IDEC, 2005.

Pinsky, I.; Jundi, S. A. R. E. L. O impacto da publicidade de bebidas alcoólicas sobre o consumo entre jovens: revisão da literatura internacional. Revista Brasileira de $\begin{array}{llll}\text { Psiquiatria, } & \text { v. } 30, & \text { n. } 4, \quad \text { p. } 362-374, \quad 2008 . & \text { https://doi.org/10.1590/S1516- }\end{array}$ 44462008005000015

Pipitone, M. A. P. Educação para o consumo de alimentos. Higiene Alimentar, v. 19, n. 132, p. 18-23, 2005.

PNUD - Programa das Nações Unidas para o Desenvolvimento. Sustentar o progresso humano: reduzir as vulnerabilidades e reforçar a resiliência. Brasília: PNUD, 2014. (Relatório do Desenvolvimento Humano, 2014). Disponível em: <http://hdr.undp.org/sites/default/files/hdr2014_pt_web.pdf>. Acesso em: 08 ago. 2019.

Saviani, D. O conceito dialético de mediação na pedagogia histórico-crítica em intermediação com a psicologia histórico-cultural. Germinal: Marxismo e Educação em Debate, v. 7, n. 1, p. 26-43, 2015. https://doi.org/10.9771/gmed.v7i1.12463

Sorrentino, M. T. T. De Tbilisi a Thessalonili, a educação ambiental no Brasil. In: Cascino, F.; Jacobi, P.; Oliveira, J. F. (Orgs.). Educação, meio ambiente e cidadania: reflexões e experiências. São Paulo: SMA, 1998. p. 27-32. 
UNESCO - Organização das Nações Unidas para a Educação, a Ciência e a Cultura. Década das Nações Unidas da Educação para um Desenvolvimento Sustentável, 2005-2014: documento final do esquema internacional de implementação. Brasília: UNESCO, 2005.

Zanirato, S. H.; Rotondaro, T. Consumo, um dos dilemas da sustentabilidade. Estudos Avançados, $\quad$ v. $30, \quad$ n. $88, \quad$ p. $77-92, \quad 2016 . \quad$ https://doi.org/10.1590/s010340142016.30880007 